\title{
LOS SOFISTASY
}

LA "DECADENCIA"

DEL MUNDO

GRIEGO: UN

INTENTO DE

REVALORIZACIÓN

Roberto Breña S.*

A mi tío Mario de la Cueva,

quien hace más de veinte años me puso en el sendero de los griegos.

\section{Introducción}

\section{Los sofistas constituyen, quizás, el} grupo de pensadores más vilipendiados en la historia de la filosofía. La razón principal es, sin duda, que la más importante y única referencia detallada sobre ellos son los Diálogos de Platón, para quien los sofistas no cran sino la encarnación misma del pensar hueco y utilitario. En el extremo opuesto, Platón coloca a su maestro Sócrates. Ya desde aquí, se pueden percibir las distorsiones en las que incurre el discípulo. Si bien es cierto que entre Sócrates y los sofistas existían claras diferencias en

* Doctorado en Historia de las Ideas Políticas en la Universidad Complutense de Madrid. 


\section{ROBERTO BREÑA}

cuanto a los fines que perseguían y que aquél nunca suscribió el escepticismo extremo de éstos, los medios utilizados eran muy similares. Sócrates no se hacía pagar por sus oyentes y no pretendía prepararlos para una actividad concreta, pero, al igual que los sofistas, centraba su interés en el hombre (desde el punto de vista ético-político y epistemológico), desempeñaba una función eminentemente crítica con respecto a su entorno social y, como ellos, argumentaba mediante recursos retóricos.

La otra razón que a nuestro juicio ha jugado un papel fundamental en la visión negativa que tradicionalmente se ha tenido de los sofistas, es que con frecuencia se les ha considerado como una de las principales causas de la decadencia de la civilización griega al terminar la Guerra del Peloponeso (431-404 a. c.). ${ }^{1}$ Constantino D. Tsatsos, por ejemplo, piensa que la sofística "llegó a ser la causa espiritual más fuerte que determinó el hundimiento del mundo griego de la antigüedad". H. D. F. Kitto, por su parte, después de afirmar que la Guerra del Peloponeso significó el final de la pólis como una fuerza creativa, se refiere a los sofistas como pensadores de segundo orden, quienes mediante su visión utilitaria de la vida y su elitismo intelectual contribuyeron de manera decisiva al individualismo, que caracterizó al siglo IV y que debilitó la cohesión de la sociedad griega hasta volverla irreconocible respecto al siglo precedente. ${ }^{2}$ Esta visión ha sido criticada por autores como W.K.C. Guthrie en el plano del pensamiento, y por Morgens H. Hansen y Claude Mossé en el nivel político y social. "Si uno piensa, ahora, en las grandes cosas que quedaban por venir - las filosofías de Platón y Aristóteles, a las que seguirán las de los estoicos, epicúreos y otros filósofos de la época

${ }^{1}$ Aunque, como trataremos de argumentar en la segunda parte de este ensayo, el término "decadencia" resulta excesivo para referirse a lo que sucedió en Grecia a partir de la derrota de Atenas frente a los espartanos en 404 a.c., lo utilizamos aquí, como en otras partes del trabajo, con las reservas que se expondrán posteriormente. Aclaramos, no obstante, que el presente trabajo no pretende negar in toto dicha decadencia, ni la participación de los sofistas en la misma, sino solamente matizar ambas. Al conjuntar esta modesta pretensión con una crítica a la interpretación exclusivamente platónica de los sofistas, creemos que el intento de revalorización aquí emprendido cumple su propósito.

${ }^{2}$ Las fuentes son, respectivamente, La filosofia social de los antiguos griegos, 1982, UNAM, p. 49 y The Greeks, 1991, Penguin Books, p. 167-69. 


\section{LOS SOFISTAS: UN INTENTO DE REVALORIZACIÓN}

helenística— no cabe duda -y esto podría ser válido para la historia griega en general- de que con los Sofistas el pensamiento griego entró no en su decadencia, sino en su primera madurez."

¿Quiénes eran los sofistas? ¿Eran un grupo homogéneo? ¿Cuáles eran sus principales doctrinas? En la primera parte de este trabajo responderemos a estas interrogantes para pasar, en la segunda, a una evaluación del papel que jugaron los sofistas en la decadencia de la sociedad griega. Al final, dedicaremos unas líneas a la importancia de la sofística para el pensamiento filosófico desde una perspectiva que va más allá de su momento histórico. 4

\section{Los sofistas y sus principales doctrinas}

Los sofistas fueron un grupo de pensadores griegos que vivieron entre la segunda década del siglo $\mathrm{V}$ (h. 480 ) y la segunda década de la centuria siguiente (h. 380). Aunque la mayoría de ellos nacieron en colonias griegas y enseñaron en muchas ciudades helénicas, su labor intelectual la desarrollaron principalmente en Atenas, el centro cultural indiscutido de la Hélade. Los dos sofistas más importantes son, sin duda, Protágoras y Gorgias, ${ }^{5}$ pero destacan también Pródico, Hipias,

${ }^{3}$ Historia de la filosofía griega (Vol. III), 1988, Gredos, p. 59 (subrayado nuestro). El libro de Hansen, lleva por título La démocratie athénienne à l'époque de Démosthène, 1993, Belles Lettres, y el de Mossé, Politique et société en Grèce ancienne. Le modele athénien, 1995, Aubier.

${ }^{4}$ Los intentos por evaluar la sofística desde una perspectiva "no ortodoxa" no son nuevos. Desde Hegel, pero sobre todo a partir de la publicación de la Historia de Grecia de Grote a mediados del siglo XIX, filósofos e historiadores de la filosofía de diversas corrientes han argumentado en contra de la interpretación puramente platónica de los sofistas. Al respecto, véase G. B. Kerferd, The Sophistic Movement, 1981, Cambridge University Press, capítulo 2 ("Towards a history of interpretations of the sophistic movement"), p. 4-14.

${ }^{5}$ Sobre estos dos pensadores (el primero nacido en Abdera, el segundo en Leontini) existe en español un texto que reúne sus fragmentos y testimonios, además de un estudio introductorio de cada uno de ellos a cargo de José Barrio Gutiérrez. Su título, Protágoras y Gorgias, Fragmentos y testimonios, 1984, Ediciones Orbis. En lo sucesivo se citará esta fuente como Fragmentos y testimonios. 


\section{ROBERTO BREÑA}

Trasímaco y Antifón. Otros sofistas menores fueron Critias, Licofrón, Alcidamante y Calicles. ${ }^{6}$

Los sofistas son los creadores del arte retórico, el cual surge de la conciencia de un hecho aparentemente trivial: la relación entre el habla y el mundo es, sobre todo, una representación. Esta representación o logos puede ser siempre superior a otra si posee ciertas características. ${ }^{7}$ El estudio de estas cualidades tenía como disciplinas fundamentales a la retórica propiamente dicha (el arte de la persuasión a través de la palabra), a la oratoria (el arte de la elocuencia) y a la dialéctica (el arte de refutar y discutir). El desarrollo y profundización de dicho estudio implicaron la creación de la lógica, la gramática y la linguística. Asimismo, la retórica sofista trajo consigo el surgimiento y desarrollo de una amplia gama de ciencias de la cultura: la epistemología, la ética, la psicología, la estética, la teoría de la religión, la sociología y la ciencia política. ${ }^{8}$ Es decir, la "revolución sofista" no fue sólo, ni primordialmente, una revo-

${ }^{6}$ Como lo señala Jacqueline de Romilly, en Les grands sophistes dans l'Athènes de Périclès, 1988, Éditions de Fallois, es muy importante distinguir a los primeros sofistas de algunos de sus seguidores, cuyos excesos retóricos desacreditaron al pensamiento sofista en general. Además de unos cuantos fragmentos "originales" de algunos de los autores arriba mencionados, se conservan dos fuentes anónimas de este pensamiento: un breve texto conocido como Discursos Dobles o Discursos Ambiguos, encontrado al final de un manuscrito del filósofo escéptico Sexto Empírico (s. II d.c.) y el Anonimo Jámblico, que consiste en una larga cita dentro de una obra de este autor neoplatónico (s. II-III d.c.). Una buena antología de prácticamente todo el pensamiento sofista que se conserva en la actualidad es la de Michael Gagarin y Paul Woodruf, Early Greek Political Thought from Homer to the Sophists, 1995, Cambridge University Press (ver sección V del texto, p. 173-311).

${ }^{7}$ La palabra griega logos tiene una multiplicidad de acepciones. En el dominio del lenguaje, significa discurso, descripción o argumento verbal. En el área del pensamiento, significa razonamiento o explicación. Por último, en relación con el mundo (aquello sobre lo cual podemos hablar y pensar) puede ser traducido por principios estructurales o leyes naturales. Véase Kerferd, op. cit., p. 83. Como lo señala Guthrie, op. cit., p. 179, a la retórica se le conocía también como el "arte de los logoi", lo que llevaba necesariamente, dada la plurisemia del término, a concepciones muy diferentes del arte del que era objeto.

${ }^{8}$ Wilhelm Nestle, Historia del espiritu griego, 1981, Editorial Ariel, p. 159. 


\section{LOS SOFISTAS: UN INTENTO DE REVALORIZACIÓN}

lución formal, sino una serie de innovaciones con contenidos diferentes en muchas áreas del conocimiento. ${ }^{9}$ Podríamos definir a la sofística como una filosofía crítica de la cultura cuyo origen, objetivo y recurso es el cuestionamiento permanente de todo lo humano.

'La lista de las áreas del saber que se desarrollaron a raíz de la sofística refleja claramente que el ser humano se había convertido en el centro del pensar filosófico, dejando en un segundo plano a la naturaleza, preocupación principal de las escuelas presocráticas. Con la sofística, el hombre, como individuo moral y como ser social, como sujeto cognoscente capaz de incidir sobre su circunstancia a través del conocimiento adquirido, se convierte en la problemática fundamental. Este cambio radical de perspectiva filosófica y la postura crítica frente a todo lo heredado son características comunes de los sofistas, así como su utilización de técnicas retóricas de diversa índole, su empirismo y escepticismo epistemológicos y, por último, su confianza en la utilidad de la labor pedagógica que realizaban. Sin embargo, aquí terminan las coincidencias. Tanto en el plano como ético como en el político, es posible encontrar posiciones muy diversas al interior del movimiento sofista. Si a ello se agrega el marcado individualismo que caracterizaba la conducta personal de los sofistas, no es casual entonces que cuando se hace referencia a la sofística se hable de "los sofistas" o de "movimiento sofista" y no de "escuela sofista".

Los sofistas trastocaron los valores fundamentales de la pólis griega a través de un cuestionamiento muy profundo de los principios que la habían sostenido hasta entonces. Sin embargo, en diversos campos, pensadores griegos de distintas escuelas presocráticas habían ya abierto el camino para el arribo de la sofística a Atenas hacia mediados del siglo

${ }^{9}$ La sofística tuvo resonancia en diversos campos de la actividad artística e intelectual de la Atenas del siglo V, sobre todo en la tragedia y en la historiografía. En lo que respecta a la primera, esta influencia es manifiesta en Eurípides, quien en varias de sus obras refleja un claro conocimiento de los nuevos problemas morales planteados por los sofistas. En cuanto a la historiografía, la influencia del pensamiento sofista sobre Tucídides es palpable a lo largo de su Historia de la Guerra del Peloponeso. Al respecto, véase las ps. 25-32 de la introducción de Francisco Romero Cruz a dicho texto, 1994, Ediciones Cátedra. 


\section{ROBERTO BREÑA}

$\mathrm{V} .{ }^{10} \mathrm{La}$ serie de transformaciones intelectuales provocadas por los sofistas son fundamentales para entender el apogeo de Atenas, ciudad que encarna, casi por sí sola, lo que se denomina comúnmente "la Grecia clásica". 11

En el plano epistemológico, los sofistas pusieron en duda la posibilidad de un conocimiento objetivo. Siguiendo a Heráclito en su polémica con Parménides, consideraban a la realidad como algo en constante cambio; "al estar comprendidos dentro de esa realidad, no sólo los objetos de conocimiento, sino también el mismo sujeto que conoce, es lógico que no pueda admitirse nada inmutable, universal y necesario". 12 La única forma de conocimiento que acepta Protágoras son las sensaciones y éstas poseen necesariamente un carácter subjetivo, es decir, relativo, como se refleja en su célebre frase: "El hombre es la medida de todas las cosas, de las que son en cuanto que son y de las que no son en cuanto que no son." ${ }^{3}$ Protágoras niega la existencia de un absoluto situado detrás de los fenómenos del mundo de los sentidos, así como detrás del mundo de los valores: ninguna representación puede pretender con mayor derecho ser verdadera, ya que todas lo son igual-

${ }^{10}$ P. ej., Kerferd, op. cit., p. 13 y 14, menciona a Heráclito, Parménides y a los pluralistas (Empédocles y Anaxágoras) como antecedentes directos de las preocupaciones sofistas sobre cuál era la naturaleza del conocimiento. Nestle, por su parte, menciona que la preocupación por el aspecto ético-espiritual del hombre que caracteriza a la sofística es posible encontrarla en autores anteriores como Jenófanes, Heráclito y Demócrito, además de los pitagóricos, op. cit., p. 113.

${ }^{11}$ Sobre la importancia de los sofistas, Romilly es categórica: "A decir verdad, no comprenderíamos nada de lo que fueron el siglo de Pericles y el 'milagro girego' si no tenemos una idea clara de la naturaleza y del alcance de su influencia." Op. cit., p. 10.

${ }^{12}$ Fragmentos y testimonios, p. 17 (la cita está tomada del primer estudio introductorio de Barrio Gutiérrez).

${ }^{13}$ Ibid., p. 51 (la fuente es Sexto Empírico). Esta doctrina del homo-mensura la expone y defiende Protágoras de la crítica socrático-platónica en el diálogo Teeteto. Es en este texto (166d) donde Sócrates refiere el supuesto desprecio de Protágoras por la sabiduría y su definición de la misma como la habilidad para hacer parecer las cosas buenas como malas y viceversa. En el Fedro (267a), Platón había caracterizado a la retórica sofística como una actividad intelectual que privilegiaba a la apariencia sobre la verdad. 


\section{LOS SOFISTAS: UN INTENTO DE REVALORIZACIÓN}

mente. ${ }^{14}$ El filósofo de Abdera no cree que los usos y costumbres de un pueblo sean mejores que los de otro. No existe, para él, una instancia que pueda decidir cuáles son los valores verdaderos; todos ellos son productos culturales humanos: la moral, el arte, la religión y el Estado. El relativismo epistemológico de Protágoras deriva pues en un relativismo sociológico.

De lo anterior se deduce lógicamente el agnosticismo de Protágoras, recogido en otra conocida frase: "Con respecto a los dioses no puedo conocer ni si existen ni si no existen, ni cuál sea su naturaleza, porque se oponen a este conocimiento muchas cosas: la oscuridad del problema y la brevedad de la vida humana". ${ }^{16}$ Esta postura frente a los dioses de la ciudad fue un elemento profundamente perturbador de la vida social griega ya que, como escribe Nestle: "La coincidencia entre la religión y el orden estatal había sido hasta entonces el presupuesto indiscutido de la polis." ${ }^{17} \mathrm{O}$, en palabras de Guthrie: "El culto a los dioses era parte integrante de la vida del Estado y una poderosa fuerza cohesiva." 18

Es cierto que, desde la fundación misma de toda ciudad griega, existía un nexo muy estrecho entre ésta y los dioses, sobre todo con las deidades

${ }^{14}$ Nestle, op. cit., p. 119-21. El relativismo sofista se correspondía a una teoría del lenguaje (desarrollada principalmente por Protágoras y Pródico) que intentaba hacer concordar a éste con la "realidad". Como lo muestra Kerferd, op. cit., p. 68-73, dicho intento no estuvo exento de contradicciones. En el Cratilo, Platón intenta resolver este problema mediante su conocida teoría de las Ideas.

${ }^{15}$ Esta nueva manera de ver a otros pueblos y culturas se derivaba en buena medida del desarrollo que habían alcanzado los estudios etnográficos por parte de los primeros historiadores y geógrafos griegos, conocidos como "logógrafos", durante los siglos VII y VI. La Historia de Herodoto, con sus relatos sobre las costumbres de los egipcios, persas, escitas, lidios y otros pueblos, jugó también un papel importante en este sentido.

${ }^{16}$ Fragmentos y testimonios, p. 73 (la fuente es Diógenes Laercio).

${ }^{17}$ Nestle op. cit., p. 179. Existía también, evidentemente, un nexo entre la religión y la moralidad en el mundo griego; sin embargo, nuestra óptica judeocristiana tiende a deformar la naturaleza de dicha vinculación y, por consiguicnte, a exagerar el impacto de la sofística en este rubro. Bowra brinda una excelente visión panorámica de la moralidad griega en el capítulo $\mathrm{V}$ de su libro The Greek Experience, 1957, Mentor Books, p. 97-114 ("The good man and the good life"). ${ }^{18}$ Op. cit., p. 225. 


\section{ROBERTO BREÑA}

tutelares; sin embargo, la crítica sofista a la religión debe ser ubicada en su contexto: la religión griega, politeísta y antropomórfica, nunca fue una doctrina unitaria y rígida, jamás tuvo un texto sagrado y nunca contó con una Iglesia organizada. Además, carecía de una cosmología revelada, de una escatología generalmente aceptada, de la idea de redención y de la noción de ortodoxia religiosa. ${ }^{19}$ Esta heterogeneidad y flexibilidad de la religión helénica ubica la crítica sofista de la misma en su justa dimensión y atenúa su carácter novedoso al colocarla dentro de un proceso continuo de discusión racional de todo lo concerniente a los dioses que se dio desde los tiempos de Hesíodo (s. VIII). El escepticismo frente a los dioses "no era ni nuevo ni revolucionario. En los últimos años del siglo VI, Jenófanes de Colofón había denunciado las viejas historias de mala conducta divina y se pronunció por un único ser divino, sólido y esférico."20

Lo anterior no pretende negar el papel protagónico que, en términos generales, jugaron los sofistas con sus críticas a las creencias religiosas tradicionales, sino atenuar una interpretación de dicha crítica que pretende dotar a la religión griega del periodo clásico de una homogeneidad, un carácter institucional y un peso específico sobre la conciencia griega que, en realidad, no poseía. Es cierto que Protágoras fue acusado de impiedad o asébeia. Sin embargo, dicho cargo era bastante común en la Atenas de Pericles y se utilizaba indistintamente para condenar a artistas

54 (Fidias), amantes/esposas de políticos (Aspasia), filósofos (Anaxágoras) o trágicos (Eurípides). ${ }^{21}$

${ }^{19}$ Kerferd op. cit., p. 163-4 y Bowra, op. cit., p. 54.

${ }^{20}$ Bowra, La Atenas de Pericles, 1974, Alianza Editorial, p. 185 y 186. Como apunta Guthrie, op. cit., p. 224, todos los filósofos presocráticos "difundieron concepciones de la religión muy lejanas del antropomorfismo de los cultos populares u oficiales basados en el panteón homérico". Volviendo a los "logógrafos", Nestle afirma que la crítica racionalista de los mitos que ellos llevaron a cabo es un síntoma "del proceso de disolución en que se encontraba la religión griega ya en el siglo VI antes de Jesucritos", op. cit., p. 85.

${ }^{21}$ A pesar de estas muestras de intolerancia, Atenas era, como lo dijo el propio Sócrates, "la ciudad de Grecia en que existe mayor libertad para hablar". Platón, Gorgias (introducción, traducción y notas de Francisco García Yagüe), Aguilar, 1989, 461e, p. 52. Respecto a la acusación hecha a Protágoras, éste abandonó la ciudad antes de que se llevara a cabo el juicio. Como se sabe, Sócrates también fue acusado de impiedad (entre otros cargos), pero rehusó escapar y fue condenado a beber la cicuta en el 399 a.c. 


\section{LOS SOFISTAS: UN INTENTO DE REVALORIZACIÓN}

Un elemento, tal vez más disruptivo para la vida en sociedad que la crítica a los dioses, es la distinción, tan cara a los sofistas, entre physis (naturaleza) y nómos (ley, convención o costumbre). ${ }^{22}$ En su dimensión específicamente jurídica, esta contraposición entre lo que era natural, y lo que era producto de convenciones humanas, necesariamente terminaba poniendo en entredicho las leyes de la ciudad. En el Protágoras, Platón pone las siguientes palabras en boca del sofista Hipias: "Varones aquí reunidos, a todos los considero parientes y conciudadanos por naturaleza, no por ley, pues lo semejante está por naturaleza emparentado con lo semejante; la ley, en cambio, que es tirano de los hombres, fuerza muchas cosas contra la naturaleza." ${ }^{23}$ En otras palabras, por primera vez en la historia de Occidente surgía la distinción entre derecho natural y derecho positivo.

Esta distinción, cuando adjudicaba a la physis un valor prescriptivo inalienable, ponía en entredicho una de las virtudes cardinales de la Grecia antigua, la justicia, y si bien podía llevar a la defensa del cosmopolitismo (entendido como fraternidad universal) por parte de sofistas como Hipias o Antifón, o a una condena de la esclavitud, como en el caso de Alcidamante, el simple hecho de cuestionar la idea de lo justo tenía un enorme efecto disruptivo sobre el funcionamiento de la sociedad griega en vista de que, como escribe Romilly, la justicia "era la regla de oro de la moral griega". ${ }^{24}$ Guthrie, por su parte, afirma que "para todos los griegos, los términos 'justicia' y 'justo' (díkaion) conllevaban una impronta de valor moral positivo: en realidad abarcaban un campo tan

${ }^{22}$ Dicha antítesis puede considerarse la dicotomía fundacional de las cuestiones más importantes debatidas por los sofistas: la religión (ilos dioses existen por physis o por nómos?), la enseñabilidad de la virtud, la organización política, la igualdad, etc. Guthrie, op. cit., p. 66 y 67.

${ }^{23}$ Protágoras (introducción, versión y notas de Ute Schmidt Osmanczik), 1994, UNAM, 337c y d, p. 36.

${ }^{24} \mathrm{Op}$. cit., p. 178 . Las otras tres virtudes cardinales de la moralidad helénica eran la sabiduría, la templanza y la valentía. El cosmpolitismo al que se hace referencia se encuentra claramente expresado en la frase de Antifón citada por Romilly, ibid., p. 139-40. Respecto a la crítica sofista a la esclavitud, Kerferd apunta que, en realidad, fueron los estoicos los primeros en desarrollar la idea que ningún hombre es esclavo por naturaleza, op. cit., p. 156. De hecho, lo mismo se podría decir sobre el cosmopolitismo. 


\section{ROBERTO BREÑA}

amplio que la idea expresada por díkaion podría decirse coextensiva con la de valor moral". 25

Decir que las leyes son una convención, opuesta a la naturaleza, puede implicar la idea de una convención útil, benéfica; pero también, y éste fue el sentido que los sofistas posteriores privilegiaron, puede referir a dichas leyes como algo que no sólo no tiene que ser obedecido necesariamente, sino que incluso debe ser rechazado, en la medida en que es contrario a la naturaleza. ${ }^{26}$ Para Kerferd, si bien las críticas sustentadas en la noción de physis minaban el sustento de las normas de conducta tradicionalmente aceptadas, su objetivo real "fue instituir un conjunto de reglas más satisfactorias en lugar de las que ya no eran aceptables en su totalidad". ${ }^{27}$ Estemos o no de acuerdo con esta interpretación, lo fundamental es que, después de los sofistas, la moral (y el derecho entendido como una extensión de la misma) ya no podía extraer su justificación de los dioses o de valores absolutos, sino que tenía que buscarla en el análisis crítico y argumentado de los problemas que plantea la vida en sociedad.

Las reacciones contra los sofistas, cuyo ejemplo más conocido en un plano no filosófico es la comedia Las nubes de Aristófanes (representada en 423 a.c.), no se hicieron esperar. ${ }^{28}$ No podía ser de otra manera frente a un grupo de profesores itinerantes que decían que no había más verdad que las impresiones sensibles de cada quien, que era imposible saber si los dioses existían y que la justicia era en buena medida una convención,

\section{${ }^{25}$ Op. cit., p. 99.}

${ }^{26}$ Debe advertirse que, incluso un escepticismo radical como el de Gorgias, nunca se tradujo en una negación del valor de la justicia. En el diálogo que lleva su nombre esto es evidente en más de una ocasión. En 454b, p. ej., afirma que la retórica tiene que ver con lo justo y lo injusto y en $457 \mathrm{a}$, b y c, es enfático al afirmar que si algunos oradores faltan a la justicia, esto no debe ser achacado a quien la enseña, sino "a quien no ha hecho el debido empleo" de la misma, Gorgias, p. 36 y $42-3$.

${ }^{27}$ Op. cit., p. 128.

${ }^{28}$ El hecho de que Aristófanes no distinga a Sócrates de los sofistas, en la crítica que hace a ambos en esta obra, puede ser que refleje su falta de refinamiento filosófico, pero refleja también que en la mente popular dicha distinción no existía o, por lo menos, no era tan clara como Platón indica en algunos de sus diálogos. 


\section{LOS SOFISTAS: UN INTENTO DE REVALORIZACIÓN}

es decir, un producto del hombre. El término "profesores" utilizado en la oración anterior debe ser enfatizado. Los sofistas se consideraban a sí mismos, antes que nada, pedagogos. Aunque en el plano epistemológico eran relativistas (Protágoras), cuando no escépticos (Gorgias), los sofistas estaban convencidos de su capacidad para transmitir conocimientos en todas las ramas del saber humano. Estos saberes constituían una educación integral que permitiría a los jóvenes desenvolverse con éxito en las diferentes instancias políticas abiertas a la participación ciudadana en la Atenas de entonces.

Con el fin de poner en tensión todas las ideas, sin importar su procedencia o nivel de aceptación, la retórica, la oratoria y la dialéctica sofistas se servían de la antilogía (la confrontación de dos argumentos dentro de una discusión) ${ }^{29}$ y de la erística (conjunto de artificios argumentativos cuya finalidad era imponerse al oponente en la discusión). ${ }^{30}$ Mediante las tres disciplinas mencionadas, los sofistas pretendían brindar una preparación que formara discípulos capaces de destacar en la vida pública. "En este arrogarse la capacidad de enseñar el dominio de la ciudadanía había algo revolucionario en relación con las ideas que sobre la ética tenía la vieja nobleza. De acuerdo a ésta, la excelencia era un derecho de nacimiento de los nobles y de nadie más. Los sofistas tocaron aquí el problema fundamental de la pedagogía: si las cualidades naturales o la educación es lo decisivo en la formación de la mente y el carácter."31

${ }^{29}$ Para Kerferd, la antilogía es "tal vez el elemento más característico del pensamiento de todo el periodo sofista", op. cit., p. 85.

${ }^{30}$ En el Eutidemo (272 a y b), Sócrates habla de erística para referirse a la capacidad de los sofistas Eutidemo y Dionisodoro de refutar mediante su habilidad de palabra absolutamente todo, tanto lo verdadero como lo falso indistintamente.

${ }^{31}$ Zeller, Outlines of the History of Greek Philosophy, 1971, Meridian Books, p. 95. Los sofistas cobraban altas sumas por sus enseñanzas, por lo que solamente los jóvenes de familias acaudaladas podían asistir a sus cursos. Algunas de estas familias, como los Alemeónidas (a la que pertenecía Pericles), habían controlado la escena política ateniense desde el siglo VI a.c. No está de más recordar que para un griego de la época clásica la noción de "vida pública" (o "vida dedicada a la pólis") comprendía un universo social y moral bastante más amplio que el nuestro. 


\section{ROBERTO BREÑA}

Esto nos lleva a una problemática con la distinción ya planteada entre physis y nómos; nos referimos al debate entre naturaleza y areté (o virtud) o, en otras palabras, la cuestión de la enseñabilidad de la virtud. ${ }^{32}$ Si ésta podía ser enseñada, ello tendría profundas consecuencias para la estructura y el funcionamiento de la sociedad. En primer lugar, como se infiere de la cita de Zeller, la enseñabilidad de la virtud puede traducirse en un medio de movilidad social, ya que, en principio, cualquier miembro de la sociedad podía aprender a ser virtuoso. Se trata, en este caso, de un elemento que atentaba contra los principios jerárquicos que, en mayor o menor medida, jugaban un papel en los regímenes políticos de todas las ciudades griegas, incluida Atenas. En segundo lugar, si la virtud es enseñable, aquellos que son capaces de enseñarla adquieren una importancia de primer orden para el cambio social y, al mismo tiempo, para el mantenimiento de la estabilidad de la pólis.

Diversas teorizaciones sofistas sobre la política y la sociedad tenían implicaciones que iban en contra del pensamiento griego tradicional. En este rubro es importante hacer notar que el individualismo exacerbado del que se suele acusar a los sofistas se vincula con el desarrollo de la democracia, en la medida en que ésta supone un respeto al individuo que era inédito en la historia de Occidente. Para la democracia ateniense, la opinión de todos y cada uno de los ciudadanos tenía valor en sí misma y, 58 por lo tanto, debía ser escuchada y tomada en cuenta. ${ }^{33}$ En este sentido,

32 "La traducción tradicional de areté por virtud obscurece hasta cierto punto la importancia de este debate. En términos generales, la virtud que denota la areté comprendía todas esas cualidades en un hombre que garantizaban el éxito en la sociedad griega y de las cuales, con razón, podía esperarse que aseguraran la admiración de sus conciudadanos; lo que iba acompañado en muchos caso por recompensas materiales de consideración." Kerferd, op. cit., p. 131. La enseñabilidad de la virtud fue un tema que preocupó mucho a Platón, como resulta evidente en el Protágoras, el Menón y La República.

${ }^{33}$ Sin embargo, el individualismo epistemológico de los sofistas y el individualismo como actitud vital que los caracterizaba, no tenían necesariamente implicaciones políticas de corte individualista en lo que respecta a la participación en los asuntos públicos (como sería el caso, después, con corrientes como el cinismo y el epicureísmo). Gorgias fue uno de los primeros y más decididos defensores de la idea de la unión de todos los griegos o panhelenismo; idea que sería retomada y ampliada por su discípulo Isócrates. 


\section{LOS SOFISTAS: UN INTENTO DE REVALORIZACIÓN}

destaca una exposición, que se puede considerar la primera justificación de la democracia participativa en la historia del pensamiento político: que hace Protágoras, en el diálogo platónico que lleva su nombre, sobre la capacidad que tienen todos los ciudadanos de compartir la virtud política $y$, por lo tanto, de participar en los asuntos de la ciudad. ${ }^{34}$ En ella sostiene que todos los hombres tienen la capacidad de adquirir una cierta competencia política y moral a través de la enseñanza. Volvemos así al debate entre physis y nómos, pero en este caso son las convenciones humanas las consideradas prioritarias. Al introducir en la discusión política términos como isonomía y homónoia (igualdad en el ejercicio de los derechos políticos y concordia política basada en la igualdad de los ciudadanos), los sofistas estaban convirtiendo a la igualdad política en un aspecto central de dicha discusión. ${ }^{35}$ Ellos fueron también los primeros en hablar de la idea de contrato social como origen y fundamento de la sociedad. ${ }^{36}$

En su libro Problemas de la democracia griega, Romilly escribe: "El debate entre Sócrates y los sofistas trata siempre sobre el sentido que debería tener una buena educación, fuente de una buena política.,37 Esta íntima relación entre educación y política fue lo que hizo de la retórica una disciplina tan importante dentro del mundo ateniense. El éxito en la vida política, en la vida de la pólis, dependía del arte retórico y esto otorgó un poder sin precedentes a quienes lograban dominarlo, así como a aquellos capaces de enseñarlo. Ahora bien, el nacimiento de la retórica en Siracusa y en Atenas a mediados del siglo $\mathrm{V}$ guarda una

${ }^{34}$ M. I. Finley considera que Protágoras formuló la única teoría democrática del mundo griego, El nacimiento de la política, Editorial Crítica, 1986, p. 164 (nota 7). Sobre Protágoras como pensador político y su marcado contraste con Platón en este campo, véase Kerferd, op. cit., p. 139-47.

${ }^{35} \mathrm{Al}$ respecto, véase Kerferd, op. cit., p. 149-53. El término griego isegoria (derecho a tomar la palabra en la Asamblea) también tenía claras vinculaciones con la propuesta política de Protágoras. Finley, op. cit., p. 182.

${ }^{36}$ Según Romilly, op. cit., p. 195-7, Protágoras, Hipias, Antifón y Licofrón trataron el tema del contrato. Sin embargo, Kerferd, op. cit., p. 128 y 147, piensa que esta atribución no se justifica en los casos de Protágoras y Licofrón. En cualquier caso, se trata solamente de precursores de una idea central en la historia del pensamiento político. A este respecto, véanse las precisiones de Guthrie, op. cit..p. 139 , nota 1.

${ }^{37}$ Problèmes de la démocratie grecque, 1975, Hermann, p. 186. 


\section{ROBERTO BREÑA}

relación directa con la democracia. Ya Aristóteles había hecho notar que el surgimiento de la retórica en Siracusa en esos años había coincidido con la caída de la tiranía y con la instauración de un régimen democrático. En el caso de Atenas, de lo dicho hasta aquí se desprende también una clara vinculación entre retórica y democracia. El lugar privilegiado que ocupa la discusión (el debate, la deliberación) dentro del arte retórico y su énfasis en la idea de que todos los argumentos, incluso los aparentemente más débiles y menos populares en un determinado momento, tienen algo que aportar a dicha discusión, son elementos que chocan frontalmente con cualquier visión elitista de la política. Es por ello que un autor como Guthrie considera que la retórica es el arte democrático "par excellence", ya en que su florecimiento es inconcebible bajo regímenes tiránicos. ${ }^{38}$

Es cierto que el vínculo entre retórica y democracia se diluiría poco a poco en una relación más amplia, la que se establecería entre la retórica y la política en general, relación que caracterizaría a todo el mundo antiguo. No obstante, es importante retener esta vinculación (aquí solamente apuntada) entre educación, retórica y democracia en la Atenas de los siglos V y IV a.c.

\section{La decadencia del mundo griego a partir de la derrota ateniense}

Tras el asesinato del reformador democrático Efialtes en 457 a.c., uno de sus seguidores, de nombre Pericles, iniciaba su exitosa carrera política, la cual no terminaría sino con su muerte en 429 a.c. Con el tiempo, este político ateniense, el más grande estadista de la Grecia clásica, se convertiría en el protector de Protágoras en particular y de las ideas sofistas en general. Este periodo, así como las tres últimas décadas del siglo, constituyen la época en que la sofística se desenvuelve y alcanza su máximo desarrollo. 39

${ }^{38}$ Guthrie, op. cit., p. 181.

${ }^{39}$ En el siglo II d.c. floreció en Atenas, así como en otras ciudades griegas del Asia Menor y en Roma, un movimiento retórico que se conoce comola "segunda sofística". Aunque importante desde una perspectiva literaria, su trascendencia desde el punto de vista filosófico es prácticamente nula. Al respecto, véase la introducción de María Concepción Giner Soria a Vidas de los Sofistas de Filóstrato, 1982, Gredos, p. 7-55. 


\section{LOS SOFISTAS: UN INTENTO DE REVALORIZACIÓN}

La asamblea o ecclesia, el consejo o boulé, los tribunales y otros puestos públicos ocupados por ciudadanos; todas eran instancias democráticas de gobierno funcionando activamente y constituían la realidad política ateniense durante esos años. En este contexto pudo darse el surgimiento y desarrollo de un conjunto de pensadores, pedagogos y críticos sociales como lo fueron los sofistas. La retórica y la oratoria, medios para el debate y la confrontación de ideas que ellos proponían como actividad permanente, se convirtieron en instrumentos idóneos para el desarrollo político y social de la democracia ateniense. ${ }^{40}$ Este aspecto de la política ateniense, novedoso a mediados del siglo $\mathrm{V}$ a.c., pierde ese carácter cincuenta años más tarde. A partir de la muerte de Pericles, no surgió ningún líder político que tuviera interés en proteger y promover a los sofistas y sus ideas. Fueron sustituidos por una escuela retórica cuyo interés se centraba exclusivamente en la oratoria. A lo largo del siglo IV a.c. esta escuela, fundada por Isócrates, el retórico más importante de la época, rivalizaría con la Academia platónica por brindar una educación rigurosa a los jóvenes atenienses.

Sobre la casualidad que existe entre el contexto esbozado más arriba y la sofística, Romilly escribe: "Sin una cierta situación material y política, los pensadores, tal vez, no podrían ejercer una influencia realmente amplia; pero, a la inversa, sin los pensadores la situación no evolucionaría de manera tan clara o tan radical." ${ }^{41}$ Esta coincidencia entre una determinada situación socio-política y la sofística nos habla de una causalidad

${ }^{40}$ Robert Cohen calcula que el aparato político administrativo ateniense requería para su funcionamiento de 8,000 servidores públicos a mediados del siglo V. Ver Atenas, una democracia, 1985, Ediciones Orbis, p. 71. En Atenas, es sabido, las mujeres, los metecos (extranjeros) y los esclavos estaban excluidos de la vida política pública. El mismo autor (en una estimación demasiado elevada si la comparamos con otras) calcula la población total de la ciudad en ese tiempo en alrededor de 450,000 personas, de las cuales sólo 30,000 podían participar políticamente, ibid., p. 92.

${ }^{41}$ Les grandes sophistes dans..., p. 165. Sobre esta relación, esta misma autora afirma: "Si cada pensador en cada momento debe mucho de su inspiración a las condiciones políticas, sociales y culturales del momento, el ejemplo de los sofistas prueba bastante bien que lo inverso es, por lo menos, igualmente cierto: al dar una forma precisa y lúcida a las aspiraciones latentes del momento, los intelectuales le confieren una fuerza considerable y casi irresistible." Ibid., p. 277. 


\section{ROBERTO BREÑA}

que no sólo no es unidireccional sino que, como con cualquier otro movimiento intelectual, es muy difícil establecer la magnitud de las influencias recíprocas. Lo cierto es que la democracia ateniense constituía un ambiente propicio para el desarrollo de un pensamiento como el de los sofistas y que el cenit de su labor crítica coincide con los años de "mayor vitalidad" de la asamblea ateniense. El uso de la expresión anterior se refiere al hecho de que, a partir del 404 a.c., la ecclesia no volvería a jugar el papel que había jugado desde las reformas de Efialtes. Como ha mostrado Hansen, buena parte de sus poderes, en lo que a política interna se refiere, pasaron a manos de los tribunales y de las comisiones legislativas conformadas por los nomotetës. Esto es lo que el historiador danés llama la "democracia reformada" de.la Atenas del siglo IV a.c., la cual se distanció de los principios democráticos radicales que los atenienses habían seguido el siglo anterior y que habían provocado una serie de crisis políticas y de catástrofes militares que no debían repetirse. ${ }^{42}$

Diversos factores jugaron un papel importante en los cambios que se dieron en la mentalidad ateniense durante las tres últimas décadas del siglo $\mathrm{V}$ a.c.: la guerra con Esparta, la peste que asoló a Atenas al principio de la misma, la guerra civil que dicho conflicto desencadenó entre los atenienses y la desmedida ambición de éstos, no sólo a nivel individual, sino como ciudad rectora de un imperio que mostraba cada vez más un 62 carácter profundamente autocrático. ${ }^{43}$ Los sofistas "de segunda generación", en un contexto social como el que se desprende de los factores enumerados, desvirtuaron muchas ideas del pensamiento sofista original, a tal punto que llegó a establecerse una relación directa entre sofística e inmoralismo. ${ }^{44}$ Esta vinculación, simbolizada por un supuesto contraste

${ }^{42}$ Op. cit., p. 182-3 y 346-7. En relación con la transición del siglo $\mathrm{V}$ al IV a.c. en el aspecto político, Mossé, op. cit., p. 178, concluye que no se puede decir que la soberanía del pueblo haya sido reemplazada por la soberanía de la ley (o, en otras palabras, la asamblea por los tribunales), pero agrega que sí se dio una limitación de la soberanía popular en la medida en que la política se profesionalizó, se hizo más técnica (sobre todo a raíz del desarrollo de la oratoria), y, en consecuencia, aumentó el número de ciudadanos "pasivos".

${ }^{43}$ Romilly, Les grands sophistes dans..., p. 160-3.

${ }^{44}$ Un buen ejemplo de lo distantes que estaban los primeros sofistas de sostener posturas inmorales, es el alegato en favor de la virtud at ribuido a Pródico y refcrido por Jenofonte, en el libro segundo de los Recuerdos de Sócrates (introducción, 


\section{LOS SOFISTAS: UN INTENTO DE REVALORIZACIÓN}

moral irreductible entre Sócrates y los sofistas, marcaría a la sofística de manera indeleble, provocando durante siglos una serie de interpretaciones parciales y sesgadas de ella.

Baste el caso de Protágoras para ilustrar este punto. A pesar de su relativismo epistemológico, el pensamiento de Protágoras, como lo muestra ampliamente el diálogo platónico que lleva su nombre, era un pensador profundamente preocupado por la areté política: un conjunto de virtudes, entre las que destacaba la justicia, que son consideradas imprescindibles por el filósofo de Abdera para la sobrevivencia de la pólis. "Él, por consiguiente, puso extraordinariamente de relieve la ley y declaró que eran las leyes del estado y la opinión pública las maestras del bien y que esta enseñanza comenzaba con la infancia y modelaba la personalidad de un hombre. Cuanto más escéptico se volvía Protágoras acerca de los dioses, tanto más firmemente se aferraba a su creencia en la ley. Era su baluarte contra el escepticismo nihilista y su confianza en el desarrollo de las sociedades civilizadas. ${ }^{\text {"45 }}$ En las referencias con las que contamos sobre él, no podemos encontrar una sola línea en contra de la justicia y sí, en cambio, una clara preocupación por la vida cívica. Sin embargo, su relativismo podía llevar, como de hecho lo hizo, hacia el inmoralismo mencionado líneas arriba. Lo mismo se puede decir de otros planteamientos sofistas. La distinción entre physis y nómos podía derivar, como en el caso de Protágoras, en una defensa de la democracia, pero también podía desembocar en la "ley del más fuerte" de Trasímaco o Calicles. $^{46}$

traducción, y notas de Juan Zaragoza), 1993, Gredos, p. 66-70. La deferencia con la que Platón trata en más de una ocasión a Protágoras y a Gorgias, indica que él estaba consciente del contraste entre los primeros sofistas y sus seguidores. "Los viejos sofistas eran hombres honorables y altamente respetados, a quienes no era extraño que sus ciudades natales encomendaran misiones diplomáticas." Zeller, op. cit., p. 97.

${ }^{45}$ Bowra, La Atenas de Pericles, p. 189.

46 Respecto a Calicles, el diálogo platónico Gorgias es la única referencia histórica con la que se cuenta sobre él. Como argumenta persuasivamente Romilly, Les grands sophistes dans..., p. 182-7, si los sofistas hubieran defendido tesis como las que Platón le atribuye en dicho diálogo, no había tenido necesidad de "inventar" a este personaje (cuya existencia real pone en duda esta autora), sino que hubiera podido atribuirlas a alguno de los sofistas conocidos históricamente. 


\section{ROBERTO BREÑA}

¿Qué se quiere decir cuando se afirma que la decadencia de Grecia se inició con la derrota ateniense en 404? Si bien Atenas nunca volvería a gozar de la influencia política que tuvo en el mundo helénico durante la segunda mitad del siglo $\mathrm{V}$, el régimen político democrático que la caracterizó durante ese periodo, y que constituía el principal resorte de su vigor y dinamismo social, no sufrió modificaciones sustanciales. Tan solo un año después, en 403 a.c., la democracia fue restaurada y Atenas no volyió a tener un gobierno oligárquico hasta la derrota definitiva frente a los macedonios en 322 a.c., simbolizada por la trágica muerte de Demóstenes ese mismo año. "La democracia recibió un golpe traicionero el 404 a.c.; pero, después de un breve periodo de oligarquía en el momento de la victoria espartana, la democracia se restableció y lo hizo con extraordinaria calma, moderación y buen sentido, para sobrevivir otros ochenta años. Y durante este periodo proporcionó, como lo había hecho desde 462 a.c., un gobierno pacífico, moderado, eficiente y popular al mayor y más complejo estado de Grecia.

Frente al argumento de que fue a partir del desenlace de la Guerra del Peloponeso que se hicieron patentes los abusos en los que incurrió la democracia, se puede argüir que ya desde los comienzos del conflicto, demagogos como Cleón habían mostrado los excesos en que aquélla podía caer. De hecho, desde muchas décadas antes, el abuso del ostra-

64 cismo como arma política había puesto en evidencia dichos excesos. ${ }^{48}$ En última instancia, como ya se apuntó, las reformas que los propios griegos atenienses realizaron a sus instituciones políticas, a partir de la restauración democrática en 403 a.c., apuntaban a una limitación de los poderes no sólo de la asamblea, sino también de los dirigentes políticos, y a un reestablecimiento del respeto a las leyes.

${ }^{47}$ W. G. Forrest, La democracia griega, 1966, Ediciones Guadarrama, p. 38. En el año 462 a.c., el ya mencionado Efialtes había reducido drásticamente el poder del Areópago, antiguo consejo de nobles. La importancia de esta reforma la resume el mismo Forrest cuando afirma que después de esa fecha el ateniense medio era conservador, estaba deseoso de conservar lo que tenía, "por la simple razón de que en todos los puntos capitales tenía lo que deseaba", ibid., p. 221.

${ }^{48}$ Sobre la ambición individual desmedida que supuestamente se presentó como consecuencia de la sofística, y cuyo ejemplo más notable sería Alcibíades, lo hecho por Temístocles sesenta años antes o por Hipias (hijo del tirano Pisístrato) a finales del siglo VI a.c., bastan para comprobar que dichas actitudes no fueron privativas de una determinada época de la historia ateniense. 


\section{LOS SOFISTAS: UN INTENTO DE REVALORIZACIÓN}

La utilización del año 404 a.c. como la fecha que marca el inicio de la decadencia de Grecia debe ser vista con cautela porque tiende a simplificar la historia griega al considerar a Atenas como un bloque social, político, militar, económico y cultural completamente homogéneo en el que todo surge (y, por lo tanto, todo se derrumba) al mismo tiempo. 49 Es claro que todos estos aspectos están interrelacionados pero, en cualquier caso, el "derrumbe" no fue ni tan generalizado ni tan uniforme como a veces se pretende.

Fijar el inicio del declive del pueblo griego en 404 a.c. reforzaría, incluso, el argumento de considerar a los sofistas como una causa más, y no la más importante, de dicho declive, en la medida en que se considera que la causa del mismo fue sobre todo una derrota militar. ${ }^{50}$ Es claro que la pérdida del imperio marítimo ateniense, a raíz del descalabro militar frente a Esparta, incidió negativamente sobre el desarrollo económico, tal como se había dado durante buena parte del siglo $\mathrm{V}$ a.c., pero ello no llevó a la pérdida de la estabilidad social. ${ }^{51}$ Asimismo, la derrota en el 404 a.c. provocó que Atenas perdiera el lugar que había ocupado en el contexto político griego desde las Guerras Médicas. La ciudad, no obstante, fue capaz de mantener casi intacta su estructura institucional interna durante muchas décadas más. "Dicho en otras palabras, más que de decadencia ["déclin"] se debe hablar de transformaciones, de adaptación a una situación nueva nacida de la Guerra del Peloponeso."

${ }^{49}$ Dentro del campo de la cultura, ya se señaló lo inapropiado de este enfoque en lo relativo a la filosofía, pero se puede decir lo mismo respecto a la oratoria, la escultura, la astronomía y la matemática. Se tiende a olvidar que Demóstenes, Isócrates, Praxíteles y Eudoxo son contemporáneos de Platón y Aristóteles.

50 "La decadencia que siguió a la caída de Atenas en 404 se debía a la derrota y al agotamiento que la precedió. Si los sofistas tuvieron algún papel en esto fue más bien como víctimas que como instigadores." Bowra, La Atenas de Pericles, p. 198.

${ }^{51}$ Como ha señalado Mossé, op. cit., p. 228 , la situación económica realmente desfavorable se limitó a los años inmediatamente posteriores a la Guerra del Peloponeso. Los líderes políticos atenienses más destacados durante el siglo IV a.c. no fueron ya los estrategas militares de la centuria precedente, sino hábiles administradores que supieron mantener sanas las finanzas públicas durante casi todo el siglo. ${ }^{52}$ Mossé, op. cit., p. 229. Refiriéndose a la pólis griega del siglo IV a.c., Finley escribe: "Decadencia' es una palabra engañosa y peligrosa para usarse en este contexto: tiene connotaciones biológicas que son inadecuadas y evoca un continuo movimiento descendente que es ostensiblemente falso." Finley, The Ancient Greeks, 1963, Penguin Books, p. 90. 


\section{ROBERTO BREÑA}

Algunas enseñanzas sofistas influyeron, indudablemente, en el clima de escepticismo moral que inundó Atenas al final de la guerra. Sin embargo, antes de condenar a la sofística en su conjunto, debe hacerse la distinción entre las doctrinas originales y la utilización posterior que de ellas se hizo. Además, tanto estas doctrinas como sus "deformaciones" deben ser inscritas dentro de sus respectivos contextos. No hacerlo, lleva a exagerar el papel que los sofistas jugaron en la pérdida de interés en los asuntos públicos y que es posible percibir en algunos aspectos de la vida ateniense durante la dilatada transición entre los siglos $\mathrm{V}$ y IV a.c.

Más allá del efecto que la sofística tuvo en el corto plazo sobre la evolución social y política de Atenas, debe considerarse el papel desempeñado por sus pensadores desde una perspectiva histórico-filosófica más amplia. Ello nos llevaría a una evaluación más objetiva del papel que los sofistas jugaron en el debilitamiento de la pólis griega.

Se puede decir, sin temor a exagerar, que los sofistas anuncian o prefiguran muchos de los principales aspectos del pensamiento filosófico tal como se ha dado hasta nuestros días: piénsese, por ejemplo, en el propio Platón, ${ }^{53}$ en algunos de los temas más importantes del estoicismo, en el "debate epistemológico" de los siglos XVII y XVIII (desde Descartes hasta Kant) o en la filosofía del lenguaje de este siglo. ${ }^{54}$ Las

53 Respecto a la influencia de los sofistas sobre Platón, Kerferd escribe: "...prácticamente todos los aspectos del pensamiento de Platón tienen su punto de partida en la reflexión de éste sobre problemas planteados por los sofistas...", op. cit., p. 173. Algunos autores de la Antigüedad afirmaban que toda $\mathrm{La}$ República de Platón estaba contenida en las Antilogías de Protágoras. Aunque muy probablemente se trate de una exageración, el simple hecho de que aquel texto haya sido referido de esta maneranos dice bastante sobre el más aventajado de los sofistas. Ver Fragmentos y testimonios, op. cit., p. 76.

54 Conste que hablamos solamente de "nuncios" o "prefiguraciones". En realidad, no se les podía pedir más, si tenemos en cuenta que la filosofía estaba dando apenas sus primeros pasos. Sobre la discusión de si los sofistas son o no filósofos, nos parece que no hay razón para extenderse demasiado. Como apunta Kerferd (op. cit., p. 174), todo depende de lo que entendamos por filosofía. Aquí también está presente el fantasma de Platón, en el sentido de que para el fundador de la Academia el mundo fenómenico (el que interesaba a los sofistas) no podía ser un objeto genuino de conocimiento. Además, si se establece una relación apodíctica entre filosofía y sistema o sistematicidad, Platón se convierte, sin duda, en el padre de la filosofía y los sofistas estarían condenados a no ser entonces nada más que eso, "sofistas". 


\section{LOS SOFISTAS: UN INTENTO DE REVALORIZACIÓN}

preocupaciones teóricas detrás de los autores y corrientes mencionados son las mismas inquietudes intelectuales de los sofistas, un grupo de filósofos cuya labor crítica constituye un elemento esencial para entender el esplendor de la Grecia clásica y, al mismo tiempo, un movimiento muy importante en la historia del pensamiento occidental. 